\title{
Artemisia annua Stems a New Sustainable Source for Cellulosic Materials: Production and Characterization of Cellulose Microfibers and Nanocrystals
}

\author{
Heriarivelo Risite ${ }^{1} \cdot$ Mohamed Hamid Salim ${ }^{2}$ - Bricharles T. Oudinot ${ }^{1} \cdot$ El-houssaine Ablouh ${ }^{2} \cdot$ Heriniaina T. Joyeux $^{1}$. \\ Houssine Sehaqui ${ }^{2}$. Jean Hugues A. Razafimahatratra ${ }^{3}$. Abou El Kacem Qaiss ${ }^{4}$. Mounir El Achaby ${ }^{2}$. \\ Zineb Kassab ${ }^{2}$ iD
}

Received: 29 April 2021 / Accepted: 2 December 2021 / Published online: 23 January 2022

(C) The Author(s), under exclusive licence to Springer Nature B.V. 2021

\begin{abstract}
In this study, Artemisia annua stem waste was identified, for the first time, as a potential natural source to produce cellulose microfibers (CMF), as well as cellulose nanocrystals (CNC) with unique functionalities by using various organic acids. The $\mathrm{CMF}$ extraction was carried out using alkali and bleaching treatments, while the $\mathrm{CNC}$ were isolated under acid hydrolysis by using sulfuric acid (S-CNC), phosphoric acid (P-CNC), and hydrochloric acid / citric acid mixture (C-CNC). The CMF and CNC physicochemical, structural, morphological, dimensional, and thermal properties were characterized. CMF with a yield of 53\%, diameter of 5 to $30 \mu \mathrm{m}$ and crystallinity of $57 \%$ were successfully obtained. In contrast, CNC showed a rod-like shape with an aspect ratio of 53, 95, and 64 and a crystallinity index of 84, 79, and 72\% for S-CNC, P-CNC, and C-CNC, respectively. Results suggested that the type of acid significantly influenced the structure, morphology, and thermal stability of CNCs. Based on these results, Artemisia апnиa stem waste is a great candidate source for cellulose derivatives with excellent characteristics.
\end{abstract}

Mounir El Achaby

mounir.elachaby@um6p.ma

Zineb Kassab

zineb.kassab@um6p.ma

1 Laboratoire de Physique et Environnement, Université de Toliara, 601 Toliara, Madagascar

2 Materials Science, Energy and Nano-Engineering Department (MSN), Mohammed VI Polytechnic University (UM6P), Lot 660 - Hay Moulay Rachid, 43150 Ben Guerir, Morocco

3 Laboratoire de Chimie organique, Université de Toliara, 601 Toliara, Madagascar

4 Composites and Nanocomposites Center (CNC), Moroccan Foundation for Advanced Science, Innovation and Research (MAScIR), Rabat Design Center, Rue Mohamed El Jazouli, Madinat El Irfane, 10100 Rabat, Morocco 


\section{Graphical Abstract}

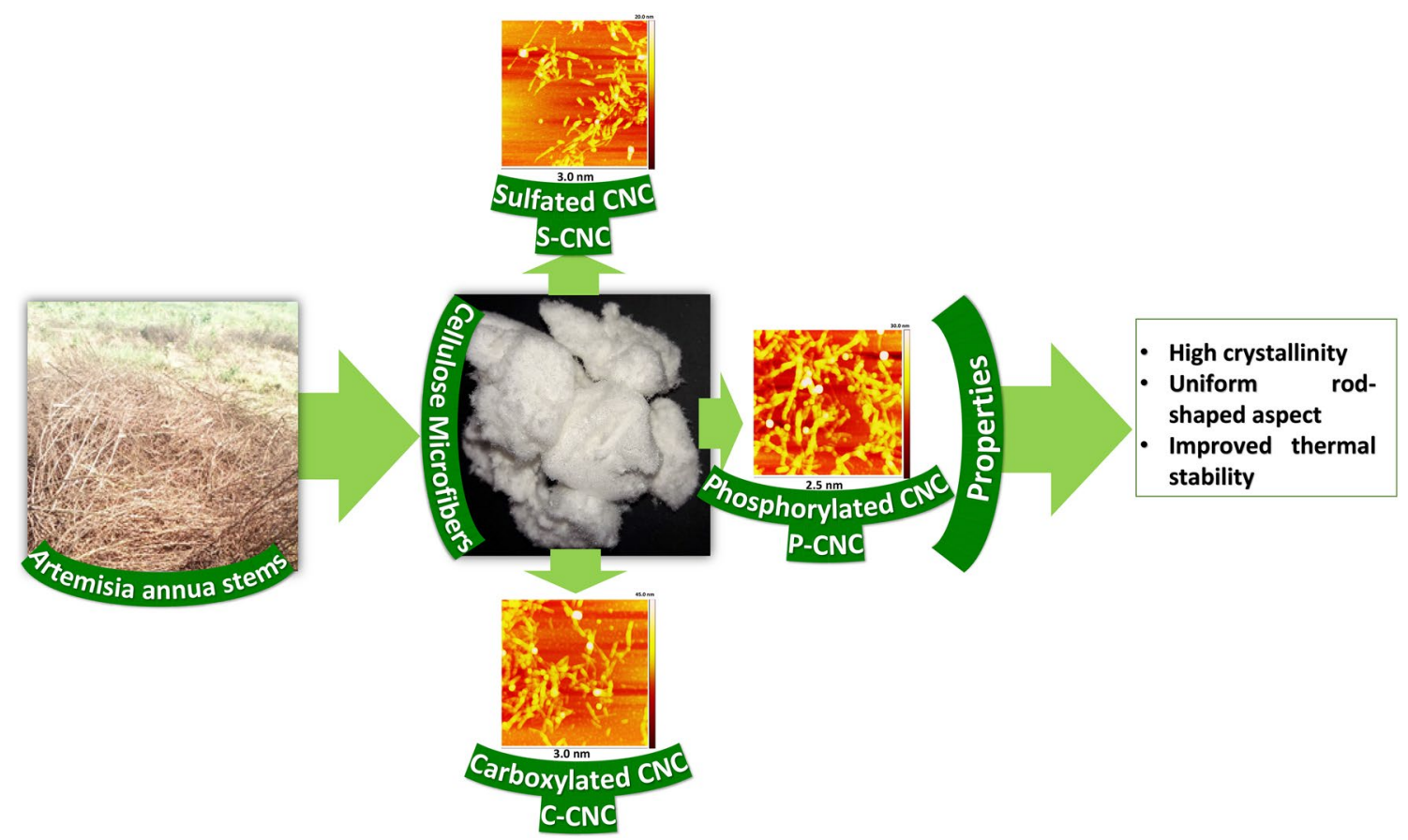

Keywords Cellulose microfibers · Cellulose nanocrystals $\cdot$ Artemisia annua $\cdot$ Renewable resource

\section{Statement of Novelty}

Different industries such as the pharmaceutical and agrifood sectors produce huge amounts of renewable agricultural waste, which could be considered a good cellulose source. Upgrading biomass into valuable products is the best way to overcome these limitations. Therefore, this paper presents novel research on using Artemisia аппиа stem waste, a new non-conventional unexplored cellulose resource, to isolate cellulose microfibers (CMF) via alkali and bleaching treatments and cellulose nanocrystals (CNC) with unique properties using different acid hydrolysis. The effects of the hydrolysis using sulfuric, phosphoric, and citric/hydrochloric acids on the morphology, structure, and properties of the resultant $\mathrm{CNC}$ were investigated. The methods provided here are a very versatile and simple procedure for preparing $\mathrm{CNC}$ that is thought to be a better alternative to the generally used, extensive, multistep, and time-consuming postfunctionalization processes.

\section{Introduction}

Cellulose, the most widely available renewable biomacromolecule available on the earth, and is widely used because of its biodegradability, biocompatibility, and chemical stability [1-5]. The major source of cellulose is wood [6-8]. However, with the increasing consumption of wood resources, deforestation and global climate change have steadily increased interest in agricultural products and by-products as an alternative source of cellulose $[6,9,10]$. Agricultural waste is the most abundant green renewable and sustainable resource residue on earth [10-12]. In this sense, these sources constitute an excellent alternative to produce novel value-added materials that represent an economic advantage for industries such as the food and packaging sectors, guided by the prominence of ecology and green chemistry [13-16]. However, its exploitation constitutes an essential solution for agricultural biomass. In recent years, these bio-based sources have attracted immense research interest to develop a new approach that can add a high value to these residues by joining novel material functions and minimizing the impact on the environment $[10,14,17,18]$. Among this biomass, it can be mentioned spruce bark, tomato plant residue, sago seed shells, acacia bark, tea leaf, garlic straw residue, and corn stover, which are the aim of several studies on the extraction of cellulosic micro and nanomaterials that hold promise in many different applications such as packaging, biomedical, energy storage, catalysis, etc. [1-5, 13, 19-21]. However, there are still several types of biomass that have not yet been exploited in this way, such as Artemisia апnиа (Artemisia апnиa L.) stem waste, which the plant 
has long been grown and used in herbal medicine as early as $168 \mathrm{BC}$, particularly in ancient China [22], and also it has been used as a source of anti-malarial drugs [23, 24]. Researchers are currently investigating its use in COVID-19 treatment and, more broadly, as a medication for respiratory infections $[25,26]$.

Artemisia апnиa plant is also grown in several other countries such as Madagascar, India, Thailand, Australia, Brazil, Switzerland, Netherlands, and France [23]. Moreover, it is reported that the plant is adaptable to various types of soil [27]. The worldwide dry weight of the Artemisia апnи a plant harvest ranges from 2 to $6.8 \mathrm{t} / \mathrm{ha}$ in a field where the annual planting density varies from 1 to 20 plants $/ \mathrm{m}^{2}$ [28]. The plant is best harvested in the budding flower state, where the whole plant is harvested and cut into branches, left to dry either in the sun or else in an oven, and the dry branches are shaken or pounded to remove the leaves from the stem [29]. The leaves are then transferred for further processing, mostly to the pharmaceutical industries, while the stems are dumped as waste [29]. Hence, the exploitation of Artemisia annua plants to extract bioactive molecules will generate stem waste rich in lignocellulosic fibers, which can be used as an essential bio-based source for the extraction of cellulosic materials and their derivatives. Additionally, the global cellulose production from all resources is expected to rise significantly, from $\$ 250$ million in 2019 to $\$ 783$ million in 2025 [1, 30]. Hence, the current work adds value to Artemisia anпиa stem residues as a source of cellulosic materials.

Many processes can be applied to remove compounds surrounding the pure cellulose to extract cellulose fibers from biomass sources [8, 16, 31]. Researchers used chemical methods such as alkalization and bleaching treatments [8]. The role of the two treatments above is the removal of noncellulosic components presented in the raw matter, namely lignin, hemicellulose, and other extractive substances, leading to the production of purified cellulose microfibers (CMF) [8, 32]. CMF consists of a mixture of amorphous and crystalline regions and exhibits a fiber diameter generally of several micrometers $[6,33]$.

The use of acid hydrolysis process to breakdown the purified cellulose fibers is the most widely applied technique, where the cellulose fibers are subjected to concentrated acid to remove the amorphous domains of the cellulose chains and leaving the crystalline domains unaltered, named cellulose nanocrystals (CNC) [1, 6, 9]. Hydrolysis conditions such as temperature, reaction time, the concentration used, and type of acid; need to be controlled during the acid hydrolysis process because the change of these factors directly affects $\mathrm{CNC}$ characteristics [6]. In the hydrolysis process, various forms of inorganic acids can be used, including sulfuric acid $\left(\mathrm{H}_{2} \mathrm{SO}_{4}\right)$ [9], phosphoric acid $\left(\mathrm{H}_{3} \mathrm{PO}_{4}\right)$ [1], a mixture of citric acid $\left(\mathrm{C}_{6} \mathrm{H}_{8} \mathrm{O}_{7}\right)$, and hydrochloric acid $(\mathrm{HCl})$ [1]. The hydrolysis by sulfuric acid attaches anionic sulfate groups to the cellulose surface, while phosphoric acid generates phosphate groups $[1,6]$. Hydrochloric acid hydrolysis produces hydroxyl groups on the surface, whereas hydrolysis using the mixture of hydrochloric acid and citric acid was reported to result in carboxylate functionalized CNC [1]. These CNC have attracted huge interest as a novel nanomaterial due to its excellent mechanical properties in nanocomposite materials [33-35].

To the best of our knowledge, the isolation of pure $\mathrm{CMF}$ and CNC from Artemisia annua stems have not been reported in the literature. Thus, this study aims to exploit the available and unexploited Artemisia апnиa stem waste as a bio-resource to produce $\mathrm{CMF}$ and $\mathrm{CNC}$ with different surface functionalities. The use of sulfuric acid, phosphoric acid, and citric/hydrochloric mixture acid hydrolysis processes resulted in the isolation of sulfated CNC (S-CNC), phosphorylated CNC (P-CNC), and carboxylated CNC (C-CNC), respectively. Furthermore, the obtained CMF and $\mathrm{CNC}$ (S-CNC, P-CNC, and C-CNC) properties were studied in terms of their morphology, structure, crystallinity, size, and thermal stability.

\section{Experimental Details}

\section{Materials}

Raw Artemisia annua stem waste (R-AS) as cellulosic raw material for extracting $\mathrm{CMF}$ and $\mathrm{CNC}$ were obtained from Madagascar. The raw plant was first dried, the dry leaves were removed, and the stems were collected and crushed. All used chemicals such as sulfuric acid (95-97\%), hydrochloric acid (37\%), phosphoric acid (85\%), sodium hydroxide, citric acid (99.5\%), acetic acid (99\%), and sodium chlorite (80\%) were obtained from Sigma Aldrich.

\section{Cellulose Microfibers (CMF) Isolation}

The extraction of CMF from stem waste of the Artemisia аппиа plant was directed through successive isolation of hemicelluloses, lignin, and other non-cellulosic components such as proteins, waxes, and fats via washing, alkaline, and bleaching treatments as often reported in previous works [6, 33]. $10 \mathrm{~g}$ of raw Artemisia аппиа stem waste (R-AS) were first treated with distilled hot water, followed by an alkaline treatment using $\mathrm{NaOH}(4 \mathrm{wt} . \%)$ at $80{ }^{\circ} \mathrm{C}$ for $2 \mathrm{~h}$ to obtain $6.5 \mathrm{~g}$ of alkali-treated Artemisia annиa fibers (AT-AS) (Fig. 1), which is equivalent to $65 \%$ yield of initial R-AS. Afterward, to produce CMF, the alkali-treated fibers were treated 3 times using a solution made up of equal parts (v:v) of acetate buffer $(75 \mathrm{~mL}$ glacial acetic acid/27 $\mathrm{g}$ of sodium hydroxide $/ 1 \mathrm{~L}$ of distilled water) and aqueous $\mathrm{NaClO}_{2}$ in 


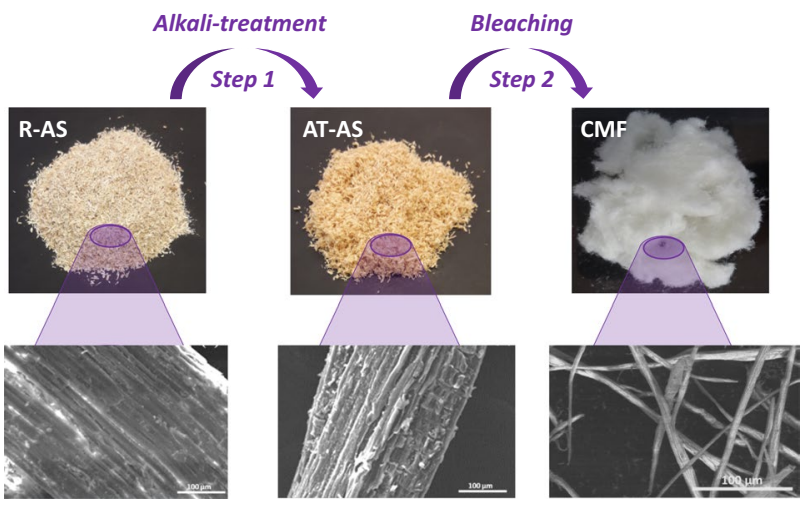

Fig. 1 Digital images of raw Artemisia annua stem waste (R-AS), alkali-treated fibers (AT-AS), cellulose microfibers (CMF) on top, and their corresponding SEM images below

water $(1.7 \mathrm{wt} \%)$. The fibers/liquid ratio was $1 / 20(\mathrm{~g} / \mathrm{mL})$. After washing and drying, $5.3 \mathrm{~g}$ white-colored fibers (53\% yield regarding the initial mass of R-AS) were obtained and named CMF (Fig. 1).

\section{Preparation of Cellulose Nanocrystals (S-CNC, P-CNC, and C-CNC)}

Three types of CNC were obtained from CMF fibers by using sulfuric, phosphoric, and a mixture of hydrochloric/citric acid hydrolysis. As demonstrated in Fig. 2, CNC suspensions were obtained after acid hydrolysis and left to cool at ambient temperature. The suspensions were then repeatedly washed using distilled water by multiple rinsing and centrifugation steps until reached a neutral $\mathrm{pH}$. The suspensions were further probe sonicated continuously for $15 \mathrm{~min}$ in an ice bath. Finally, the obtained suspensions were transformed into a dried form using the freeze-drying process (Fig. 2). The yield of obtained CNC was $18 \%, 28 \%$, and $26 \%$ for S-CNC, P-CNC, and C-CNC, respectively, compared to the initial R-AS.

\section{Characterization Techniques}

The chemical composition of the Artemisia stem waste was done using TAPPI (Technical Association of the Pulp and Paper Associations) standard methods. Firstly, the sample was prepared according to the standard TAPPI T $210 \mathrm{~cm}-03$ method. The composition of the raw fibers was determined according to the following methods: cellulose and hemicellulose (TAPPI T $203 \mathrm{~cm}-99$ ), acid-insoluble lignin (TAPPI T 222 om-02), moisture (TAPPI T 550 om-99), and ash (TAPPI T 211 om-02). On the other hand, the holocellulose content was determined according to Wise et al. method [36]. FTIR spectroscopy analysis was carried out using FTIR, PerkinElmer Spectrum 2000 equipped with an ATR accessory. The FTIR spectra were taken in the transmittance mode in the range of 4000-600 $\mathrm{cm}^{-1}$ with a resolution of $4 \mathrm{~cm}^{-1}$ and an accumulation of 16 scans. X-ray diffraction (XRD) characterization was performed using a D2 PHASER diffractometer BRUKER using copper radiation $(\lambda=1.54056 \AA)$ in the $2 \theta$ range of $5-50^{\circ}$ with a step size of $2^{\circ}$ at room temperature. The crystallinity index $(\mathrm{CrI})$ and the crystallite size $(\mathrm{CrS})$ were calculated following Nam (Eq. 1) and Scherrer (Eq. 2) equations, respectively [37-39].

$$
\begin{aligned}
& C r I=\frac{A_{c r}}{A_{c r}+A_{a m}} \\
& C r S=\frac{K \lambda}{\beta_{1 / 2} \cos 2 \theta}
\end{aligned}
$$

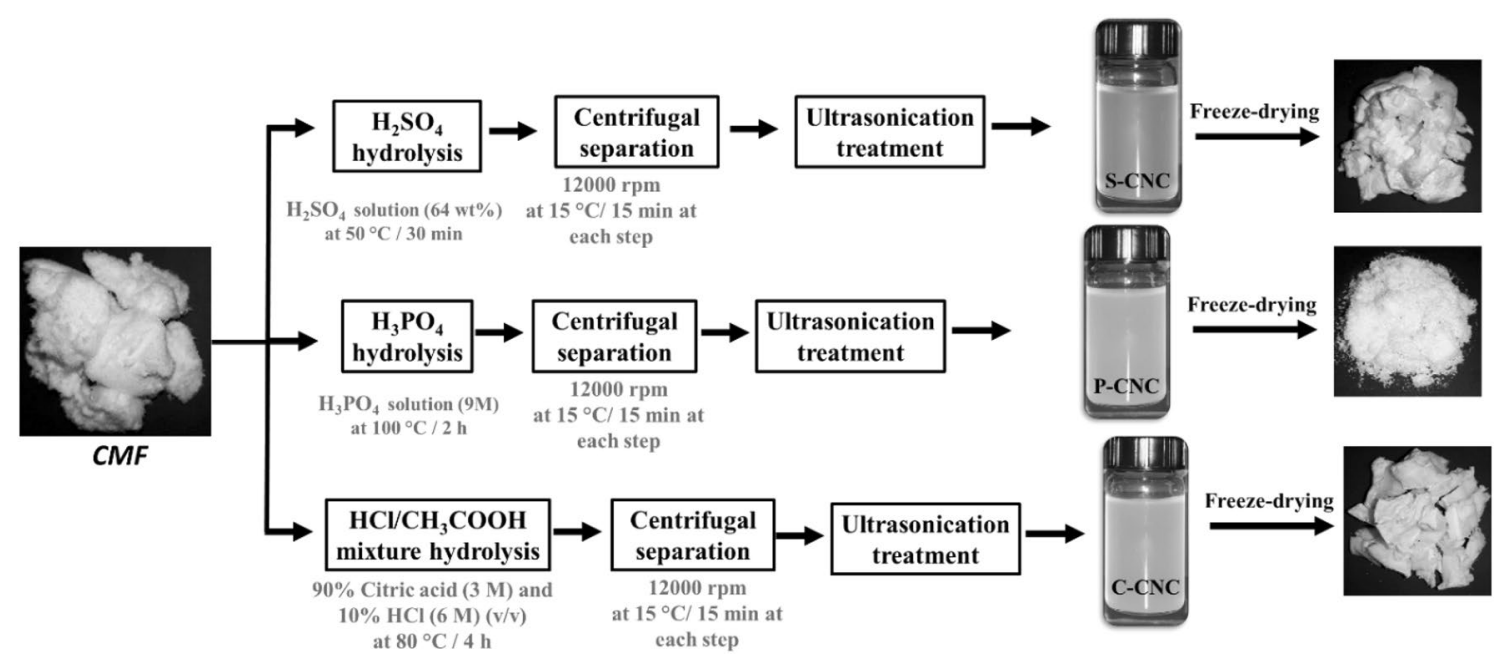

Fig. 2 Overall steps for the preparation of cellulose nanocrystals (S-CNC, P-CNC, and C-CNC) 
where $A_{c r}$ represents the area under the calculated pattern of crystalline cellulose. $A_{a m}$ is the area under the pattern calculated for the amorphous content. $\lambda$ is the $\mathrm{X}$-ray wavelength $(\lambda=1.5418 \AA), K$ is the Scherrer constant (0.94), $2 \theta$ is the Bragg's angle $\left(22^{\circ}\right)$ and $\beta_{1 / 2}$ is the full width at the half maximum of the XRD peak. Scanning electron microscopy (HIROX SH 4000 M SEM apparatus) was used to observe the morphology of the samples. The SEM analysis was operated at an accelerating voltage of $15 \mathrm{kV}$. Samples were attached on SEM specimen holders with double-sided carbon tape and coated with carbon by using a high vacuum sputter coater. SEM images were statistically analyzed using ImageJ software to determine the diameter and length size of the samples. Atomic force microscopy (AFM) images of $\mathrm{CNC}$ were recorded using a Veeco Dimension ICON apparatus. The measurements were made at room temperature in tapping mode at a scan rate of $1.5 \mathrm{~Hz}$. The thermal properties of all samples were also studied using thermogravimetry (Discovery TGA, TA instruments). The samples $(\approx 10 \mathrm{mg})$ were heated from 30 to $700{ }^{\circ} \mathrm{C}$, under nitrogen with an airflow of $25 \mathrm{~mL} / \mathrm{min}$ and a heating rate of $10{ }^{\circ} \mathrm{C} / \mathrm{min}$.

\section{Results and Discussions}

\section{Chemical Structure of Cellulosic Microfibers and Nanocrystals}

Lignocellulosic materials are generally composed of cellulose, lignin, and hemicellulose, meaning that the fiber's main composition includes different functional groups such as aromatics, alcohols, alkanes, esters, carboxylates, and ketones $[10,40]$. From the chemical composition results, it was found that R-AS contains $56 \%$ cellulose, $24 \%$ lignin, $1.29 \%$ moisture, and $3.12 \%$ ash. R-AS had a similar cellulosic composition to maize, hemp, and Humulus japonicus stems [33, 41, 42]. These findings suggest that R-AS could be used as an alternative to non-conventional cellulose sources [33].

FTIR analysis was performed to reveal the chemical structure changes that occurred after the alkaline, bleaching treatments and cellulose nanocrystals preparation. The FTIR spectra of R-AS, AT-AS, and CMF were obtained, as shown in Fig. 3a. The untreated raw Artemisia annua stem waste (R-AS) showed cellulose characteristic bands at 3334, 2919 , and $1023 \mathrm{~cm}^{-1}$ corresponding to stretching vibrations of hydrogen bond $\mathrm{O}-\mathrm{H}, \mathrm{C}-\mathrm{H}$ symmetrical stretching, and glycosidic ether band $\mathrm{C}-\mathrm{O}-\mathrm{C}$, respectively $[20,33,43]$. The absorption band around $1636 \mathrm{~cm}^{-1}$ was assigned to the $\mathrm{O}-\mathrm{H}$ bending of water [44]. The sharp peak at $1428 \mathrm{~cm}^{-1}$ can be attributed to $\mathrm{C}-\mathrm{H}$ bending vibrations of cellulose [33]. Three peaks that are present only in the spectrum of R-AS at $1735 \mathrm{~cm}^{-1}, 1507 \mathrm{~cm}^{-1}$, and $1234 \mathrm{~cm}^{-1}$, which correspond respectively to $\mathrm{C}=\mathrm{O}$ stretching vibration, $\mathrm{C}=\mathrm{C}$ vibration of the aromatic skeleton, and $\mathrm{C}-\mathrm{O}$ stretching vibration of acetyl or aryl functional groups from hemicellulose and lignin fractions $[9,45,46]$. These three bands practically disappear in the spectra of AT-AS and CMF after eliminating lignin and hemicelluloses after chemical treatments, which aligns with earlier reported studies in the literature [2, 20, 47]. Therefore, this confirms the stability of cellulose chemical structure and the total removal of lignin and hemicellulose molecules after chemical treatments [32].

The spectra of isolated CNC (Fig. 3b) revealed the same peaks in all wavenumbers like CMF spectra. However, the only difference is the intensity growth of cellulosic characteristics bands, indicating that the cellulose content was increased during different chemical treatments starting from R-AS and ending with extracted CNC. It has been reported that the use of sulfuric acid hydrolysis of cellulose induced a sulfate half-ester reaction between sulfuric acid and cellulose surface, which led to the occurrence of sulfate half-ester groups on the surface of CNC $[6,33]$. On the other hand, phosphoric acid hydrolysis results in P-CNC with inserted phosphate groups on the surface [8]. While the carboxylate groups can be formed by the esterification reaction between the hydroxyl groups of cellulose and the carboxyl groups of citric acid, leading into carboxylated CNC (C-CNC) [7]. Hence, it is worth noting that sulfate and carboxylate groups were introduced on the surface of S-CNC, P-CNC, and $\mathrm{C}-\mathrm{CNC}$ during the sulfuric, phosphoric and citric/hydrochloric acid hydrolysis, respectively. The band relative to sulfate and phosphate negatively charged groups is generally observed at 1202 and $1230 \mathrm{~cm}^{-1}$, respectively, which are overlapped with the main characteristics of cellulose molecules in the FTIR spectrum of S-CNC, and P-CNC samples. In the case of C-CNC prepared using hydrochloric acid / citric acid mixture, a new peak at $1731 \mathrm{~cm}^{-1}$ was observed, due to the functionalization with the carboxylate groups through an esterification reaction between the $\mathrm{O}-\mathrm{H}$ groups of cellulose and the $\mathrm{COOH}$ groups of citric acid [48]. The FTIR results confirmed the successful extraction of surfacefunctionalized CNC from the newly Artemisia annua stems. Overall, all typical absorption bands present in the isolated S-CNC, P-CNC, and C-CNC spectra are almost identical to the spectra of CNC obtained from tomato plant residue [1], hemp stalks [33], and sago seed shells [2].

\section{Crystalline Structure of Cellulose Microfibers and Cellulose Nanocrystals}

Cellulose commonly consists of both crystalline and amorphous regions $[4,49]$; the crystalline structure of cellulose is due to hydrogen bonding interactions and Van der Waals forces between adjacent cellulosic monomers [19]. Identification of cellulosic materials types and evaluation 

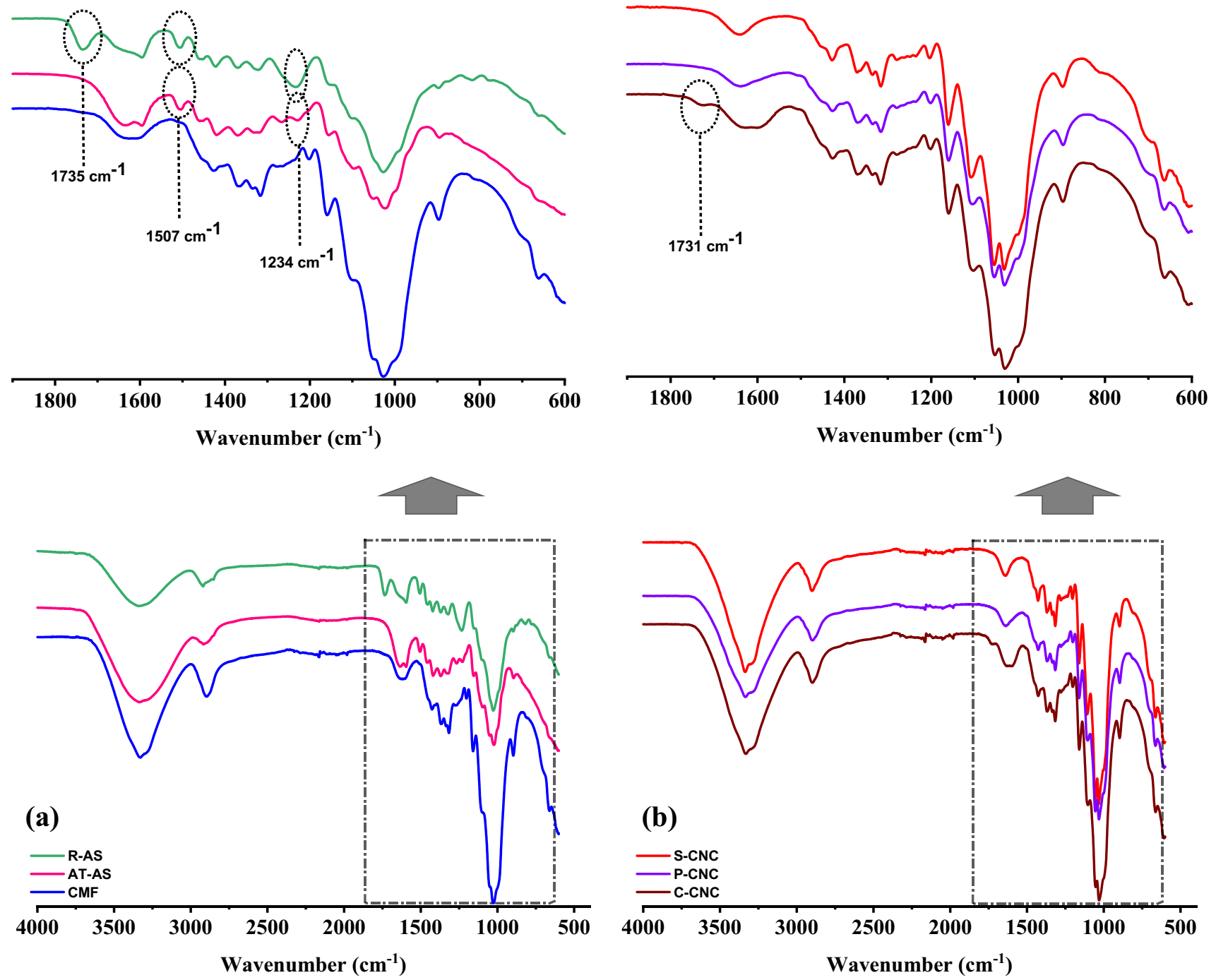

Fig. 3 FTIR spectra of a R-AS, AT-AS, and CMF; and b the isolated cellulose nanocrystals (S-CNC, P-CNC, C-CNC)

of crystallinity after different chemical treatment steps was determined using an X-ray diffractometer. Figure 4 presents the XRD spectra of R-AS, AT-AS, CMF, and all the obtained $\mathrm{CNC}$ after hydrolysis treatment (S-CNC, P-CNC, and $\mathrm{C}-\mathrm{CNC}$ ), whereas the value of $\mathrm{CrI}$ and $\mathrm{CrS}$ were summarized in Table 1. The R-AS and AT-AS exhibited three reflection peaks at $2 \theta=16.1^{\circ}, 22.3^{\circ}$ and $34.5^{\circ}$ (Fig. 4a), that are attributed to the crystal form of cellulosic polymorph. The R-AS sample displayed a broad peak at $2 \theta=15-19^{\circ}$, which is attributed to the overlapping of crystalline cellulose I and the amorphous cellulose, hemicellulose, and lignin [50]. This result confirms that R-AS waste fibers can be classified as lignocellulosic material [1]. On the other hand, after obtaining CMF, intense crystalline peaks were observed at $2 \theta$ value of $17.4^{\circ}, 22.9^{\circ}$, and $35.1^{\circ}$, confirming the cellulose crystalline structure and the successful removal of hemicellulose and lignin during chemical treatments.
During chemical hydrolysis, the acid attacks the amorphous parts of CMF and liberates individual crystallites via the initiation of glycosidic bonds hydrolytic cleavage, which instantly increases the crystallinity of cellulose [19]. The crystallinity index gradually increased from $57 \%$ for $\mathrm{CMF}$ to $84 \%, 79 \%$, and $72 \%$ for S-CNC, P-CNC, and C-CNC, respectively (Table 1). These findings indicate the consecutive removal of the amorphous regions during acid hydrolysis. Furthermore, the highest crystallinity of isolated cellulose nanocrystals appeared in the presence of sulfuric acid, compared with the presence of phosphoric acid (P-CNC) and hydrochloric acid/citric acid mixture (C-CNC). This difference can be due to the easy penetration of sulfite ions in more accessible amorphous regions of CMF and disordered cellulosic regions were decomposed; hence, high crystallinity was obtained [19]. Moreover, the Bronsted acidity of the acids could have affected the crystallinity of CNC [51, 52]. 

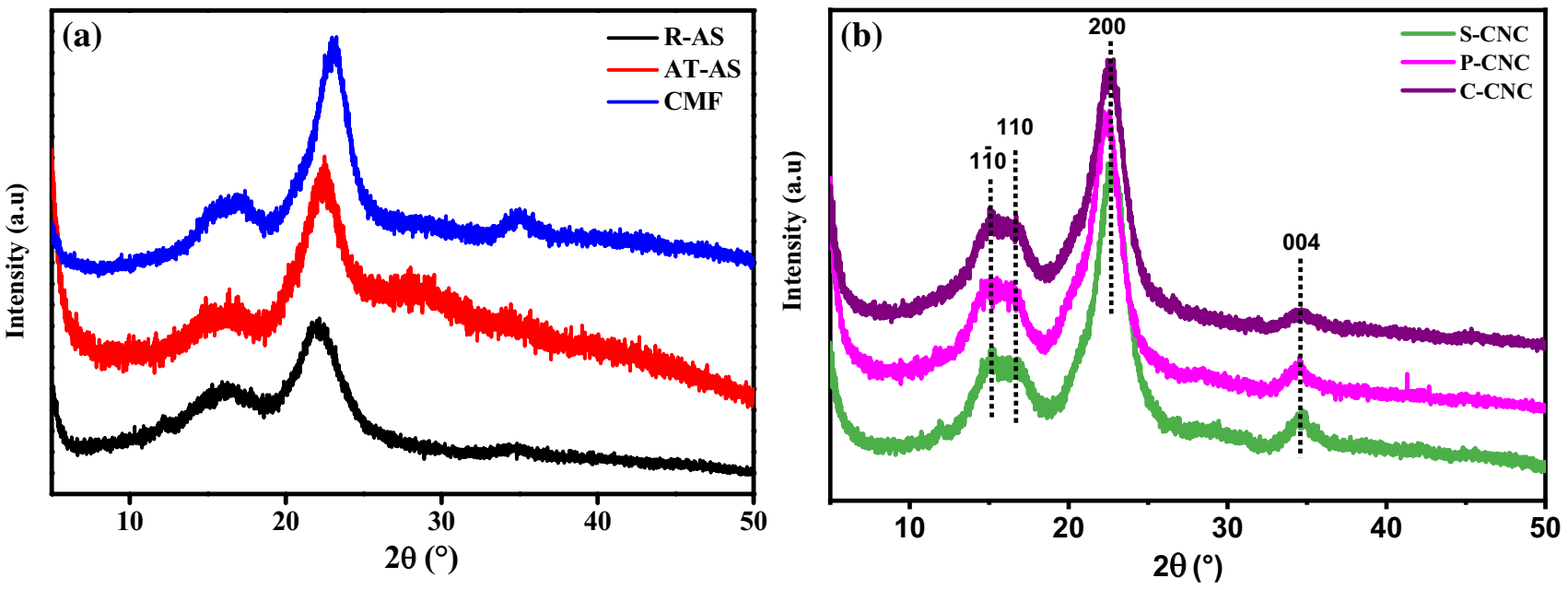

Fig. 4 XRD patterns of a R-AS, AT-AS, and CMF; and b the isolated cellulose nanocrystals (S-CNC, P-CNC, and C-CNC)

Table 1 Structural and thermal parameters of $S-C N C, P-C N C$, and C-CNC samples

\begin{tabular}{llllll}
\hline Sample & $C r I(\%)$ & $C r S(\mathrm{~nm})$ & $T_{\text {onset }}\left({ }^{\circ} \mathrm{C}\right)$ & $T_{\max }\left({ }^{\circ} \mathrm{C}\right)$ & $R(\%)$ at $700{ }^{\circ} \mathrm{C}$ \\
\hline S-CNC & 84 & 3.13 & 213 & 345 & 15.65 \\
$P-C N C$ & 79 & 2.44 & 207 & 342 & 17.04 \\
$C-C N C$ & 72 & 2.78 & 193 & 336 & 20.51 \\
\hline
\end{tabular}

Accordingly, the average crystallites size $(\mathrm{CrS})$ was determined from X-ray diffractograms by applying Scherrer's expression (Eq. 2). This calculation was made only for $\mathrm{S}-\mathrm{CNC}, \mathrm{P}-\mathrm{CNC}$, and C-CNC; based on which the $\mathrm{CrS}$ value was found to be $3.13,2.44$, and $2.78 \mathrm{~nm}$, respectively. The $\mathrm{CrS}$ depend on the acid hydrolysis type and conditions. The high value of $\mathrm{CrS}$ for $\mathrm{S}-\mathrm{CNC}$ is possibly due to rearrangement and recrystallizing of the purified $\alpha$-cellulose chains from neighboring CMF during acid hydrolysis, leading to the generation of longer crystal dimensions and high crystallinity index of CNC.

\section{Morphological Analysis of Raw and Treated Fibers}

Morphological and microstructure were investigated from the original fibers to fibers exposed to various treatments because the source of cellulose and chemical treatment process has a profound influence on the dimension and properties. The SEM images of R-AS fibers as presented in Fig. 5a, showed an average width of $100-300 \mu \mathrm{m}$ and a length is about $500 \mu \mathrm{m}$. However, the alkali-treated fibers (AT-AS) surface presents a non-uniform roughness due to the removal of the same amorphous compounds such as hemicellulose and lignin [44], and also the elimination of a large amount of the extractives molecules from the surface of the fibers
(Fig. 5b). After bleaching treatment, the cellulosic fibers (Fig. 5c-d) were disintegrated into microfibers with a diameter between 5 and $30 \mu \mathrm{m}$. For the morphological aspect, the CMF appeared smoother than fibers found after alkali treatment (AT-AS), as more hemicellulose and lignin were removed during the bleaching process. This result shows that the applied chemical treatments effectively produced individual CMF from Artemisia annua plant stems.

\section{Dimension and Aspect Ratio of Isolated CNC}

The disintegration process of CMF to CNC depends on several parameters such as the concentration of acid, type of acid, temperature, and duration of the hydrolysis process [53]. Fragmentation of CMF starts with the cleavage of amorphous regions that are not resistant to acid hydrolysis and leaving crystalline regions. This leads to the isolation of nano-sized crystals of cellulose. In this study, the successful extraction of cellulose nanocrystals under acid hydrolysis conditions was confirmed by high-resolution AFM (Fig. 6). Referring to AFM results (Fig. 6), the nanocrystals tend to agglomerate due to the strong hydrogen bonds established between the individualized crystallites.

The obtained CNC exhibited a rod-shaped aspect, as generally observed for cellulose nanocrystals isolated using acid hydrolysis $[2,13]$. By examining the AFM images (Fig. 6) using digital image analysis (Veeco Data Analysis software), the average diameter and length of the obtained CNC samples were calculated and reported (Table 2), which verified that the obtained CNC were on a nanometric scale. However, the diameter $(D)$ and length $(L)$ of the obtained S-CNC, P-CNC, and C-CNC showed some differences. The approximate diameters for cellulose nanocrystals under sulfuric acid, phosphoric acid, 
Fig. 5 SEM images of a R-AS fibers, b Alkali-treated fibers, c and $\mathbf{d}$ cellulose microfibers
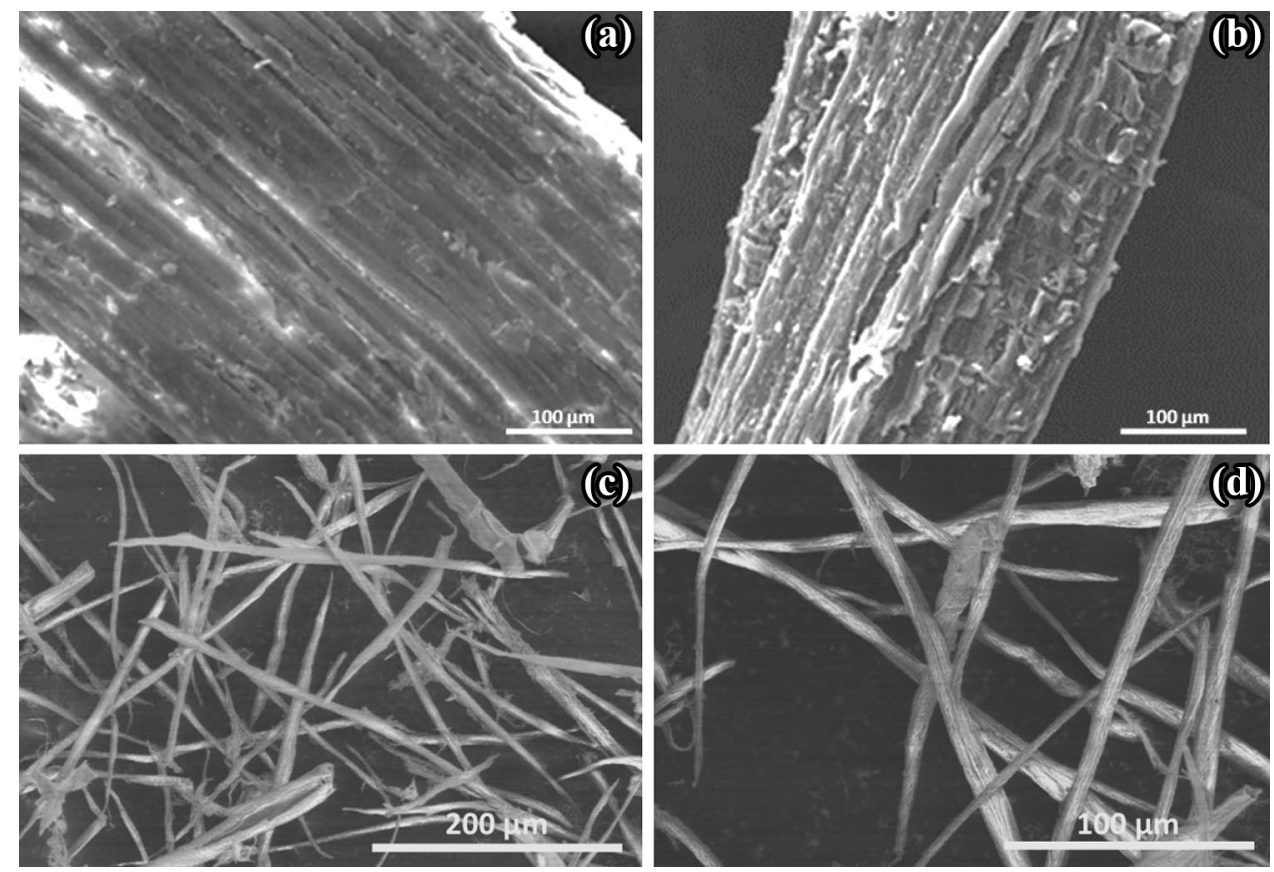

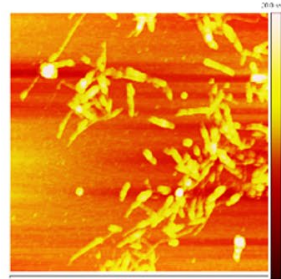

$3 \mu \mathrm{m}$

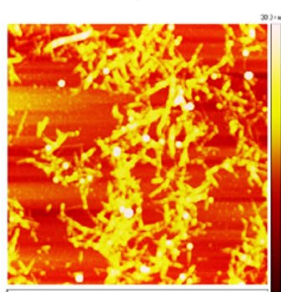

$5 \mu \mathrm{m}$

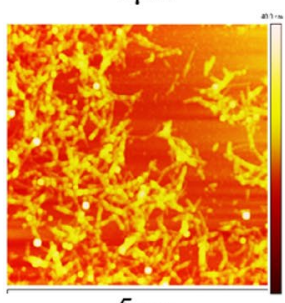

$5 \mu \mathrm{m}$

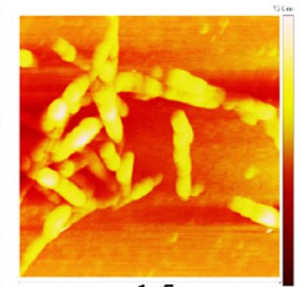

$1.5 \mu \mathrm{m}$

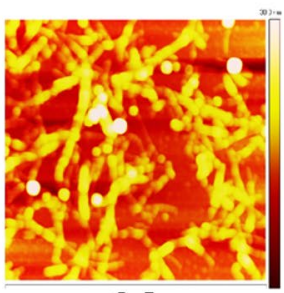

$2.5 \mu \mathrm{m}$

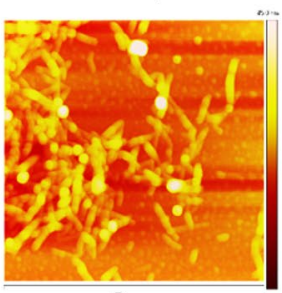

$2 \mu \mathrm{m}$ (a)

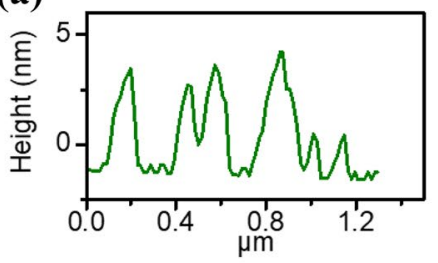

(b)
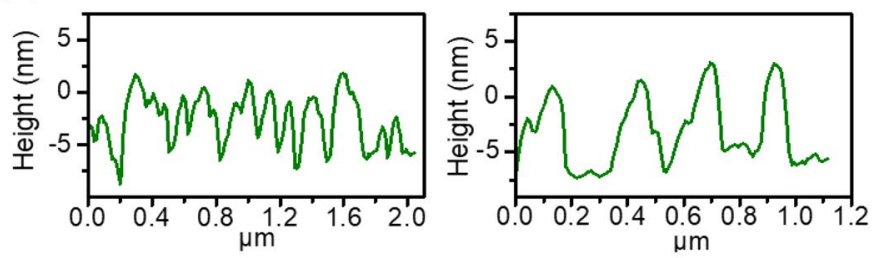

(c)

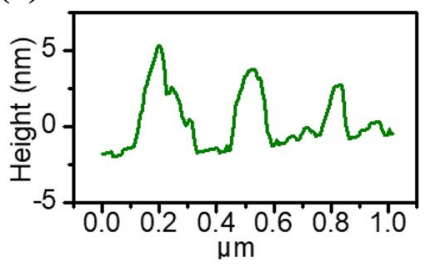

Fig. 6 AFM images and the corresponding height profiles taken along the indicated lines of a S-CNC, b P-CNC, and c C-CNC

and hydrochloric acid / citric acid mixture were found to be about 4.7, 5.3, and $7.2 \mathrm{~nm}$, respectively. These results are close to those found for $\mathrm{CNC}$ isolated from tomato plant residue, garlic straw, eggplant plant, agave tequilana, barley, and pea pods (Table 2). Similarly, the average length values were found to be ranging from 380 to $520 \mathrm{~nm}$. These results present an aspect ratio $(L / D)$ of 81 , 95, and 64 for S-CNC, P-CNC, and C-CNC, respectively. 
Table 2 Length $(L)$, diameter $(D)$, aspect ratio $(L / D)$, and hydrolysis process of cellulose nanocrystals isolated from different lignocellulosic sources

\begin{tabular}{|c|c|c|c|c|c|}
\hline Source & $L(\mathrm{~nm})$ & $D(\mathrm{~nm})$ & $L / D$ & Hydrolysis process & References \\
\hline \multirow[t]{3}{*}{ Tomato (Solanum lycopersicum L.) plant residue } & $367 \pm 101$ & $7.4 \pm 2.2$ & 49 & $\mathrm{H}_{2} \mathrm{SO}_{4}(64 \mathrm{wt} \%)$ & \multirow[t]{3}{*}[1]{} \\
\hline & $670 \pm 115$ & $6.2 \pm 2.4$ & 98 & $\mathrm{H}_{3} \mathrm{PO}_{4}(9 \mathrm{M})$ & \\
\hline & $514 \pm 131$ & $4.7 \pm 1.4$ & 67 & Citric acid $(6 \mathrm{M}) / \mathrm{HCl}(3 \mathrm{M})$ mixture & \\
\hline Garlic (Allium sativum L.) straw & 480 & 6 & 80 & $\mathrm{H}_{2} \mathrm{SO}_{4}(65 \mathrm{wt} \%)$ & [19] \\
\hline \multirow[t]{2}{*}{ Eggplant (Solanum melongena L.) plant } & $487.0 \pm 154$ & $6.7 \pm 2.1$ & 74 & $\mathrm{H}_{2} \mathrm{SO}_{4}(64 \mathrm{wt} \%)$ & \multirow[t]{2}{*}{ [9] } \\
\hline & $597.5 \pm 163$ & $6.3 \pm 2.3$ & 89 & $\mathrm{H}_{3} \mathrm{PO}_{4}(9 \mathrm{~mol} / \mathrm{L})$ & \\
\hline Agave tequilana (Agave L.) & $323 \pm 113$ & $11 \pm 4$ & 28 & $\mathrm{H}_{2} \mathrm{SO}_{4}(65 \mathrm{wt} \%)$ & {$[54]$} \\
\hline Barley (Hordeum vulgare L.) & $329 \pm 123$ & $10 \pm 4$ & 32 & $\mathrm{H}_{2} \mathrm{SO}_{4}(65 \mathrm{wt} \%)$ & \\
\hline Pea (Pisum Sativum L.) & $483 \pm 74$ & $5.4 \pm 2.3$ & 89 & $\mathrm{H}_{2} \mathrm{SO}_{4}(64 \mathrm{wt} \%)$ & {$[6]$} \\
\hline \multirow[t]{3}{*}{ Artemisia аппиа $\mathrm{L}$} & $384 \pm 93$ & $4.7 \pm 1.8$ & 81 & $\mathrm{H}_{2} \mathrm{SO}_{4}(64 \mathrm{wt} \%)$ & \multirow[t]{3}{*}{ This study } \\
\hline & $504 \pm 122$ & $5.3 \pm 1.2$ & 95 & $\mathrm{H}_{3} \mathrm{PO}_{4}(9 \mathrm{M})$ & \\
\hline & $456 \pm 105$ & $7.2 \pm 2.1$ & 64 & Citric acid $(3 \mathrm{M}) / \mathrm{HCl}(6 \mathrm{M})$ mixture & \\
\hline
\end{tabular}

\section{Thermal Stability Behavior}

The thermal degradation behavior of R-AS, CMF, and isolated cellulose nanocrystals ( $\mathrm{S}-\mathrm{CNC}, \mathrm{P}-\mathrm{CNC}$, and C-CNC) was investigated by thermogravimetric analysis, which gives information about the degradation processes over time as the temperature change. Generally, the thermal degradation of lignocellulosic materials and its derivatives implicates dehydration, depolymerization, and glycosylic unit decomposition, followed by carbonaceous species formation [53]. The same thermal behavior was seen in this study, in which all the samples exhibited a weight loss below 5\% at $<140{ }^{\circ} \mathrm{C}$ (Fig. 7), corresponding to the evaporation of moisture loosely bound to the surfaces, which is related to the hydrophilic nature of the cellulosic materials [6]. In the temperature between 150 and $700{ }^{\circ} \mathrm{C}$ (Fig. 7a and b), it can be seen that the R-AS sample showed two and three steps of the thermal degradation process under nitrogen and air atmosphere, respectively, which are well explained in the literature $[6,55,56]$. The first stage, occurring at $211^{\circ} \mathrm{C}$ for both atmospheres, is assigned mainly due to the decomposition of hemicellulose to volatile compounds, which widely exist in biomass [57]. The intensive decomposition with major weight loss takes place in the second stage on DTG curves (Fig. 7a and b) at $345{ }^{\circ} \mathrm{C}$, and $279{ }^{\circ} \mathrm{C}$ under nitrogen and air atmosphere, respectively, is due to the depolymerization, rearrangement, and pyrolysis, leading to the formation of $\mathrm{CO}$, levoglucosan, and others volatile species by the cleavage of the main cellulosic chain, the abstraction of side groups and ring-opening reactions occur in this step $[55,57]$. In this stage, it can be noticed that the main degradation DTG peak was shifted to a lower temperature under air atmosphere. The third step degradation between 365 and $455^{\circ} \mathrm{C}$ under air atmosphere based on DTG curves (Fig. 7b), could be attributed to the degradation of lignin, and the oxidative decomposition of the charred residue. Since lignin is thermally more stable, its decomposition depends on the source and composition [56, 58]. As in the case of the nitrogen atmosphere (Fig. 7b), this peak is not detected. The combustion of carbonaceous species finally occurs at higher temperatures $\left(>460{ }^{\circ} \mathrm{C}\right)$, considering that the degradation of biomass rich in polysaccharides is accelerated by oxygen; its degradation is practically completed at about $500{ }^{\circ} \mathrm{C}$. While in the nitrogen condition, the biochar was the dominant product. This result shows that R-AS contains heterogeneous constitute (hemicellulose, cellulose, and lignin).

After removing hemicellulose, lignin, and extractives during chemical treatment, the TGA analysis was performed for extracted CMF. From the TGA and DTG curves (Fig. 7a and b), the thermal degradation of CMF in both atmospheres, the first thermal event is due to break down of cellulosic components and the second event that occurs only in the air atmosphere is due to oxidation of the partially decomposed components. The CMF showed one main degradation peak temperature at around $342{ }^{\circ} \mathrm{C}$ under nitrogen atmosphere (Fig. 7a), which showed better thermal stability than the raw material $\left(211^{\circ} \mathrm{C}\right)$. This increase in thermal stability is due to increased crystallinity and intermolecular hydrogenbonded domains after eliminating non-cellulosic and amorphous components [59]. In the air atmosphere (Fig. 7b), two weight loss stages, namely oxidative fast devolatilization at $320^{\circ} \mathrm{C}$ and combustion stage at $418^{\circ} \mathrm{C}$, could be found. This degradation was mainly contributed by the oxygen in the air. The oxygen would accelerate the devolatilization by the combustion reaction with char. More importantly, the most significant difference between nitrogen and air atmosphere could be found in the third stage (combustion stage). This percentage of carbonaceous species of CMF under nitrogen atmosphere was $15 \mathrm{wt} \%$. In the air atmosphere, almost all 


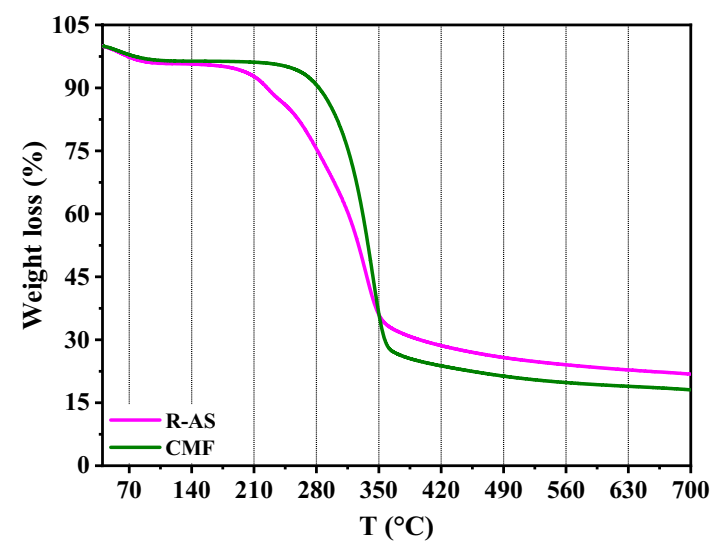

(a)
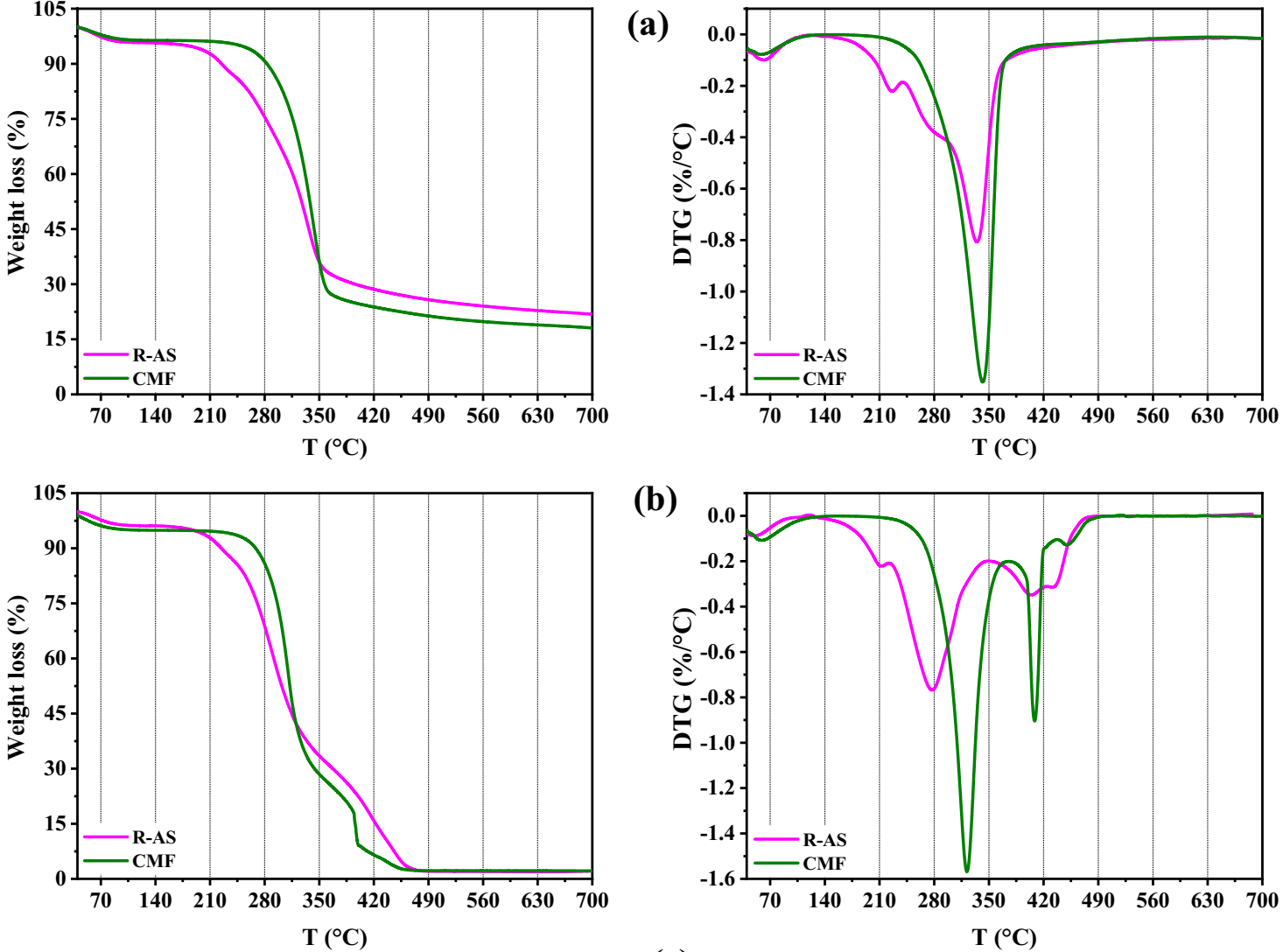

(b)
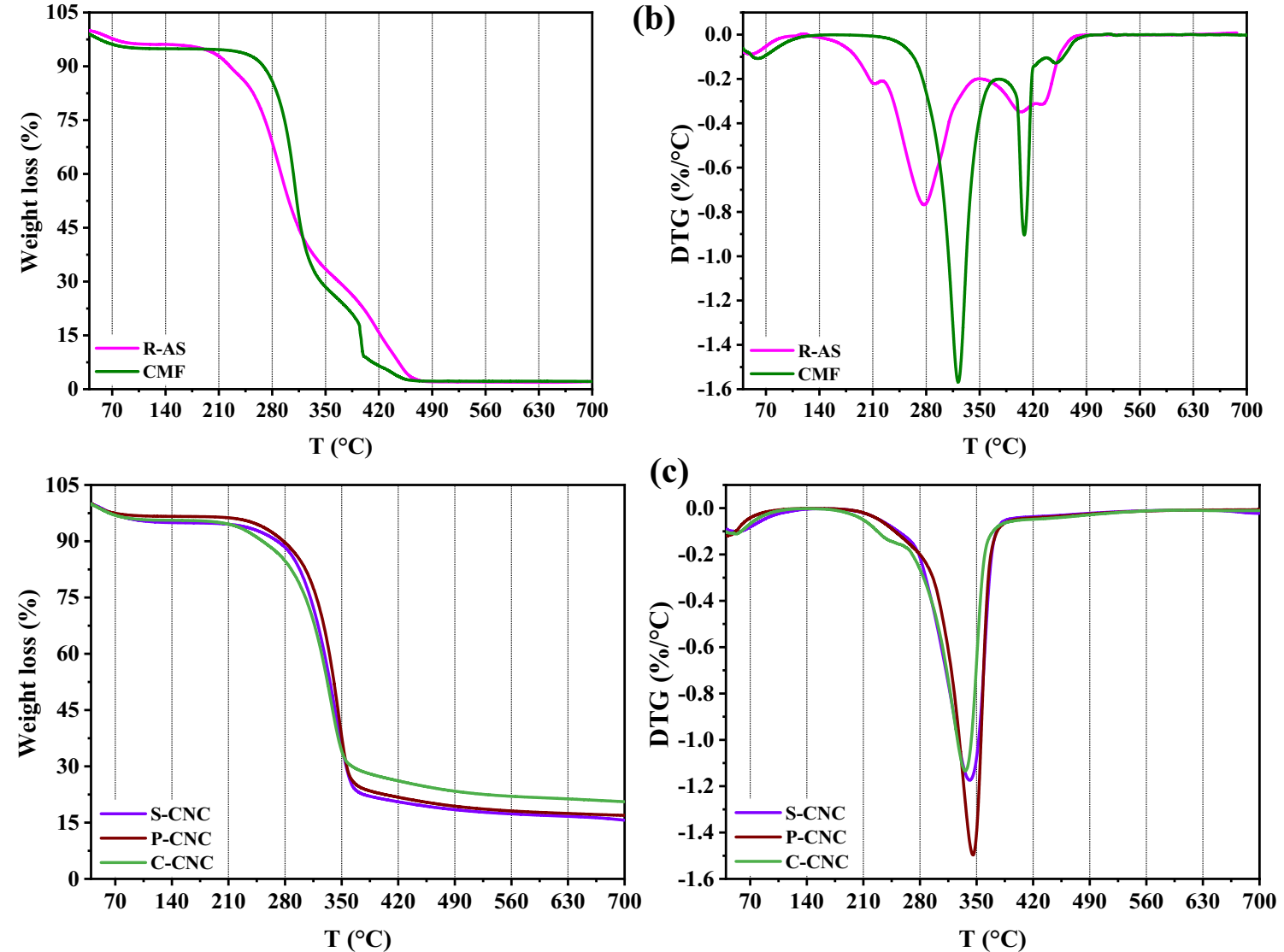

Fig. 7 TGA and DTG curves of R-AS and CMF samples under a nitrogen atmosphere and $\mathbf{b}$ air atmosphere, and of $\mathbf{c}$ S-CNC, P-CNC, and $\mathrm{C}-\mathrm{CNC}$ samples under nitrogen atmosphere

the residual carbonaceous species formed in the oxidative fast devolatilization stage was burned with oxygen and converted into $\mathrm{CO}_{2}$ and $\mathrm{H}_{2} \mathrm{O}[15,39]$.

Thermal decomposition of cellulose nanocrystals prepared under different acidic conditions results in one major peak in the high-temperature range of $335-346{ }^{\circ} \mathrm{C}$ in the DTG curve (Fig. 7c). It was observed that thermal degradation was initiated at $193{ }^{\circ} \mathrm{C}$ and $207{ }^{\circ} \mathrm{C}$ in the case of phosphoric acid and hydrochloric acid/citric acid mixture treatments, respectively. While the cellulose nanocrystals prepared using the sulfuric acid process was $213{ }^{\circ} \mathrm{C}$. Comparing to both acid processed nanocrystals $\mathrm{C}-\mathrm{CNC}$ and $\mathrm{P}-\mathrm{CNC}$, there was a significant increase in the initial degradation temperature of S-CNC (Table 1), which is higher than that extracted from other sources using sulfuric acid [19, 20]. A similar thermal property was noticed where microcrystalline cellulose extracted from giant reed using $\mathrm{H}_{2} \mathrm{SO}_{4}$ showed higher decomposition temperatures compared with different acid solutions [40]. These findings show that the different acid treatments produced $\mathrm{CNC}$ that have interesting 
thermal properties. On the other hand, the residues left after heating to $700{ }^{\circ} \mathrm{C}$ were observed to be about $15.65,17.04$, and $20.51 \%$ for S-CNC, P-CNC, and C-CNC, respectively. The higher residual amounts produced by $\mathrm{C}-\mathrm{CNC}$ are likely due to its functionalization during acid treatment [7].

\section{Conclusion}

This study was designed to prepare valuable cellulosic products from the residue of Artemisia annua stem waste, which was identified for the first time as a viable and sustainable materials source to produce cellulose microfibers and cellulose nanocrystals. Furthermore, a conventional extraction process based on alkali treatment followed by and bleaching was used to raw Artemisia annиa stem waste. The noncellulosic materials such as lignin and hemicellulose were used successfully removed. This process produced pure CMF with a diameter between 5 and $30 \mu \mathrm{m}$, with a $T_{\max }$ of $342{ }^{\circ} \mathrm{C}$. The feasibility of CNC isolation was successfully carried out by exposing the extracted CMF to sulfuric, phosphoric, and hydrochloric/citric mixture acid hydrolysis, resulting in P-CNC, S-CNC, and C-CNC, respectively. The obtained CNC have high crystallinity, a uniform rod-shaped aspect with a size distribution of 4.7-7.2 $\mathrm{nm}$ in diameter and 384-504 $\mathrm{nm}$ in length, and improved thermal stability with $T_{\max }$ of 345,342 , and $336^{\circ} \mathrm{C}$ for S-CNC, P-CNC, and $\mathrm{C}-\mathrm{CNC}$, respectively. Moreover, the crystallinity index was found to increase from $57 \%$ for CMF to 84,79 , and $72 \%$ for S-CNC, P-CNC, and C-CNC, respectively. Consequently, these findings demonstrate a potential strategy to add high value to Artemisia annua stem waste and proved that it could be used to produce valuable $\mathrm{CMF}$ and $\mathrm{CNC}$, which may be used in various applications such as polymer reinforced composites manufacturing.

Acknowledgements The authors wish to acknowledge l'Office Chérifien des Phosphates (OCP S. A) for financial support.

\section{Declarations}

Conflict of interest The authors declare that they have no conflict of interest.

Ethical Approval The article does not include human participants and/ or animals research.

Informed Consent Informed consent was obtained from all participants.

\section{References}

1. Kassab, Z., Kassem, I., Hannache, H., Bouhfid, R., Qaiss, A.E.K., El Achaby, M.: Tomato plant residue as new renewable source for cellulose production: extraction of cellulose nanocrystals with different surface functionalities. Cellulose 27, 4287-4303 (2020). https://doi.org/10.1007/ s10570-020-03097-7

2. Naduparambath, S., Jinitha, T.V., Shaniba, V., Sreejith, M.P., Balan, A.K., Purushothaman, E.: Isolation and characterisation of cellulose nanocrystals from sago seed shells. Carbohydr. Polym. 180, 13-20 (2018). https://doi.org/10.1016/j.carbpol.2017.09.088

3. Taflick, T., Schwendler, L.A., Rosa, S.M.L., Bica, C.I.D., Nachtigall, S.M.B.: Cellulose nanocrystals from acacia bark-Influence of solvent extraction. Int. J. Biol. Macromol. 101, 553-561 (2017). https://doi.org/10.1016/j.ijbiomac.2017.03.076

4. Rahman, N.H.A., Chieng, B.W., Ibrahim, N.A., Rahman, N.A.: Extraction and characterization of cellulose nanocrystals from tea leaf waste fibers. Polymers (Basel) 9, 1-11 (2017). https://doi.org/ 10.3390/polym 9110588

5. Trache, D., Thakur, V.K., Boukherroub, R.: Cellulose nanocrystals/graphene hybrids-a promising new class of materials for advanced applications, www.mdpi.com/journal/nanomaterials (2020)

6. Kassab, Z., Abdellaoui, Y., Salim, M.H., El Achaby, M.: Cellulosic materials from pea (Pisum Sativum) and broad beans (Vicia Faba) pods agro-industrial residues. Mater. Lett. 280, 128539 (2020). https://doi.org/10.1016/j.matlet.2020.128539

7. Kassab, Z., Syafri, E., Tamraoui, Y., Hannache, H., Qaiss, A.E.K., El Achaby, M.: Characteristics of sulfated and carboxylated cellulose nanocrystals extracted from Juncus plant stems. Int. J. Biol. Macromol. 154, 1419-1425 (2020). https://doi.org/10.1016/j.ijbio mac.2019.11.023

8. Ait Benhamou, A., Kassab, Z., Nadifiyine, M., Salim, M.H., Sehaqui, H., Moubarik, A., El Achaby, M.: Extraction, characterization and chemical functionalization of phosphorylated cellulose derivatives from Giant Reed Plant. Cellulose 28, 4625-4642 (2021). https://doi.org/10.1007/S10570-021-03842-6

9. Bahloul, A., Kassab, Z., El Bouchti, M., Hannache, H., Qaiss, A.E.K., Oumam, M., El Achaby, M.: Micro- and nano-structures of cellulose from eggplant plant (Solanum melongena L.) agricultural residue. Carbohydr. Polym. 253, 117311 (2021). https://doi. org/10.1016/J.CARBPOL.2020.117311

10. Ait Benhamou, A., Boussetta, A., Kassab, Z., Nadifiyine, M., Hamid Salim, M., Grimi, N., El Achaby, M., Moubarik, A.: Investigating the characteristics of cactus seeds by-product and their use as a new filler in phenol formaldehyde wood adhesive. Int. J. Adhes. Adhes. 110, 102940 (2021). https://doi.org/10.1016/J. IJADHADH.2021.102940

11. Trache, D., Hussin, M.H., Haafiz, M., Thakur, V.K.: Recent progress in cellulose nanocrystals: sources and production. Nanoscale 9, 17-25 (2017). https://doi.org/10.1039/c6nr09494e

12. Kassab, Z., Boujemaoui, A., Ben Youcef, H., Hajlane, A., Hannache, H., El Achaby, M.: Production of cellulose nanofibrils from alfa fibers and its nanoreinforcement potential in polymer nanocomposites. Cellulose 26, 9567-9581 (2019). https://doi.org/10. 1007/s10570-019-02767-5

13. Le Normand, M., Moriana, R., Ek, M.: Isolation and characterization of cellulose nanocrystals from spruce bark in a biorefinery perspective. Carbohydr. Polym. 111, 979-987 (2014). https://doi. org/10.1016/j.carbpol.2014.04.092

14. Motaung, T.E., Linganiso, L.Z.: Critical review on agrowaste cellulose applications for biopolymers. Int. J. Plast. Technol. 22, 185-216 (2018). https://doi.org/10.1007/s12588-018-9219-6

15. Eyley, S., Thielemans, W.: Surface modification of cellulose nanocrystals. Nanoscale 6, 7764-7779 (2014). https://doi.org/ 10.1039/C4NR01756K

16. Thomas, B., Raj, M.C., B, A.K., H, R.M., Joy, J., Moores, A., Drisko, G.L., Sanchez, C.: Nanocellulose, a versatile green platform: from biosources to materials and their applications. 
Chem. Rev. 118, 11575-11625 (2018). https://doi.org/10.1021/ ACS.CHEMREV.7B00627

17. Huang, S., Liu, X., Chang, C., Wang, Y.: Recent developments and prospective food-related applications of cellulose nanocrystals: a review. Cellulose 27, 2991-3011 (2020). https://doi.org/ 10.1007/s10570-020-02984-3

18. Blilid, S., Katir, N., Haskouri, J.E., Lahcini, M., Royer, S., El Kadib, A.: Phosphorylated micro- vs. nano-cellulose: a comparative study on their surface functionalisation, growth of titanium-oxo-phosphate clusters and removal of chemical pollutants. New J. Chem. 43, 15555-15562 (2019). https://doi.org/ 10.1039/C9NJ03187A

19. Kallel, F., Bettaieb, F., Khiari, R., García, A., Bras, J., Chaabouni, S.E.: Isolation and structural characterization of cellulose nanocrystals extracted from garlic straw residues. Ind. Crops Prod. 87, 287-296 (2016). https://doi.org/10.1016/j.inder op.2016.04.060

20. Larissa, L.A., Fonsêca, A.F., Pereira, F.V., Druzian, J.I.: Extraction and characterization of cellulose nanocrystals from corn stover. Cellul. Chem. Technol. 49, 127-133 (2015)

21. Trache, D.: Nanocellulose as a promising sustainable material for biomedical applications. AIMS Mater. Sci. 5, 201 (2018)

22. Wallaart, T.E., Pras, N., Beekman, A.C., Quax, W.J.: Seasonal variation of artemisinin and its biosynthetic precursors in plants of Artemisia апnиа of different geographical origin: proof for the existence of chemotypes. Planta Med. 66, 57-62 (2000). https://doi.org/10.1055/s-2000-11115

23. Aftab, T., Khan, M.M.A., Idrees, M., Naeem, M., Singh, M., Ram, M.: Stimulation of crop productivity, photosynthesis and artemisinin production in Artemisia annиa L. by triacontanol and gibberellic acid application. J. Plant Interact. 5, 273-281 (2010). https://doi.org/10.1080/17429141003647137

24. Liu, K.C.-S., Yang, S., Roberts, M.F., Elford, B.C., Phillipson, J.D.: Antimalarial activity of Artemisia апnиa flavonoids from whole plants and cell cultures. Plant Cell Rep. 11, 11-14 (1992). https://doi.org/10.1007/BF00236389

25. Haq, F.U., Roman, M., Ahmad, K., Rahman, S.U., Shah, S.M.A., Suleman, N., Ullah, S., Ahmad, I., Ullah, W.: Artemisia annua: trials are needed for COVID-19. Phyther. Res. (2020). https://doi.org/10.1002/ptr.6733

26. Larson, H.J.: A call to arms: helping family, friends and communities navigate the COVID-19 infodemic. Nat. Rev. Immunol. 20, 449-450 (2020). https://doi.org/10.1038/s41577-020-0380-8

27. Syukur, M., Lestari, E.G., Purnamaningsih, R., Yunita, R., Aisyah, S.I., Firdaus, R.: Adaptability of mutant genotypes of artemisia (Artemisia annиa L.) as result of gamma irradiation in three locations. 33, 251-257 (2011)

28. Tu, Y.: Studies on the Cultivation and Breeding of Artemisia aпnиа L. from Artemisia aпnиa L. to Artemisinins, pp. 139-161 (2017). https://doi.org/10.1016/b978-0-12-811655-5.00007-6

29. World Health Organization: WHO monograph on good agricultural and collection practices (GACP) for Artemisia annua L, pp. 1-49. WHO Press (2006)

30. Pakharenko, V., Sameni, J., Konar, S., Pervaiz, M., Yang, W., Tjong, J., Oksman, K., Sain, M.: Cellulose nanofiber thin-films as transparent and durable flexible substrates for electronic devices. Mater. Des. 197, 109274 (2020). https://doi.org/10. 1016/j.matdes.2020.109274

31. Blilid, S., Kędzierska, M., Miłowska, K., Wrońska, N., Achaby, M.E., Katir, N., Belamie, E., Alonso, B., Lisowska, K., Lahcini, M., Bryszewska, M., Kadib, A.E.: Phosphorylated micro- and nanocellulose-filled chitosan nanocomposites as fully sustainable, biologically active bioplastics. ACS Sustain. Chem. Eng. 8, 18354-18365 (2020). https://doi.org/10.1021/ACSSUSCHEM ENG.0C04426
32. El Achaby, M., Kassab, Z., Aboulkas, A., Gaillard, C., Barakat, A.: Reuse of red algae waste for the production of cellulose nanocrystals and its application in polymer nanocomposites. Int. J. Biol. Macromol. 106, 681-691 (2018). https://doi.org/10.1016/j. ijbiomac.2017.08.067

33. Kassab, Z., Abdellaoui, Y., Salim, M.H., Bouhfid, R., Qaiss, A.E.K., El Achaby, M.: Micro- and nano-celluloses derived from hemp stalks and their effect as polymer reinforcing materials. Carbohydr. Polym. 245, 116506 (2020). https://doi.org/10.1016/j. carbpol.2020.116506

34. Kassab, Z., Aziz, F., Hannache, H., Ben Youcef, H., El Achaby, M.: Improved mechanical properties of k-carrageenan-based nanocomposite films reinforced with cellulose nanocrystals. Int. J. Biol. Macromol. 123, 1248-1256 (2019). https://doi.org/10. 1016/j.ijbiomac.2018.12.030

35. Kassem, I., Ablouh, E.-H., Bouchtaoui, F.-Z., Kassab, Z., Khouloud, M., Sehaqui, H., Ghalfi, H., Alami, J., Achaby, M.E.L.: Cellulose nanocrystals-filled poly (vinyl alcohol) nanocomposites as waterborne coating materials of NPK fertilizer with slow release and water retention properties. Int. J. Biol. Macromol. (2021). https://doi.org/10.1016/j.ijbiomac.2021.08.093

36. Jonasson, S., Bünder, A., Niittylä, T., Oksman, K.: Isolation and characterization of cellulose nanofibers from aspen wood using derivatizing and non-derivatizing pretreatments. Cellulose 27, 185-203 (2019). https://doi.org/10.1007/S10570-019-02754-W

37. Shaheen, T.I., Emam, H.E.: Sono-chemical synthesis of cellulose nanocrystals from wood sawdust using acid hydrolysis. Int. J. Biol. Macromol. 107, 1599-1606 (2018). https://doi.org/10. 1016/j.ijbiomac.2017.10.028

38. Nam, S., French, A.D., Condon, B.D., Concha, M.: Segal crystallinity index revisited by the simulation of X-ray diffraction patterns of cotton cellulose I $\beta$ and cellulose II. Carbohydr. Polym. 135, 1-9 (2016). https://doi.org/10.1016/J.CARBPOL.2015.08. 035

39. Ling, Z., Wang, T., Makarem, M., Santiago Cintrón, M., Cheng, H.N., Kang, X., Bacher, M., Potthast, A., Rosenau, T., King, H., Delhom, C.D., Nam, S., Vincent Edwards, J., Kim, S.H., Xu, F., French, A.D.: Effects of ball milling on the structure of cotton cellulose. Cellulose 26, 305-328 (2019). https://doi.org/10.1007/ S10570-018-02230-X

40. Tarchoun, A.F., Trache, D., Klapötke, T.M., Derradji, M., Bessa, W.: Ecofriendly isolation and characterization of microcrystalline cellulose from giant reed using various acidic media. Cellulose 26, 7635-7651 (2019). https://doi.org/10.1007/s10570-019-02672-x

41. Jiang, Y., Zhou, J., Zhang, Q., Zhao, G., Heng, L., Chen, D., Liu, D.: Preparation of cellulose nanocrystals from Humulus japonicus stem and the influence of high temperature pretreatment. Carbohydr. Polym. 164, 284-293 (2017). https://doi.org/10.1016/J. CARBPOL.2017.02.021

42. Longaresi, R.H., de Menezes, A.J., Pereira-da-Silva, M.A., Baron, D., Mathias, S.L.: The maize stem as a potential source of cellulose nanocrystal: cellulose characterization from its phenological growth stage dependence. Ind. Crops Prod. 133, 232-240 (2019). https://doi.org/10.1016/J.INDCROP.2019.02.046

43. Naili, H., Jelidi, A., Limam, O., Khiari, R.: Extraction process optimization of Juncus plant fibers for its use in a green composite. Ind. Crops Prod. 107, 172-183 (2017). https://doi.org/10. 1016/J.INDCROP.2017.05.006

44. Kumar, A., Negi, Y.S., Choudhary, V., Bhardwaj, N.K.: Characterization of cellulose nanocrystals produced by acid-hydrolysis from sugarcane bagasse as agro-waste. J. Mater. Phys. Chem. 2, 1-8 (2014). https://doi.org/10.12691/jmpc-2-1-1

45. Kumar, A., Negi, Y.S., Bhardwaj, N.K., Choudhary, V.: Synthesis and characterization of cellulose nanocrystals/PVA based bionanocomposite. Adv. Mater. Lett. 4, 626-631 (2013). https://doi.org/ 10.5185/amlett.2012.12482 
46. Chieng, B.W., Lee, S.H., Ibrahim, N.A., Then, Y.Y., Loo, Y.Y.: Isolation and characterization of cellulose nanocrystals from oil palm mesocarp fiber. Polymers (Basel) 9, 1-11 (2017). https://doi. org/10.3390/polym 9080355

47. Tarchoun, A.F., Trache, D., Klapötke, T.M.: Microcrystalline cellulose from Posidonia oceanica brown algae: extraction and characterization. Int. J. Biol. Macromol. 138, 837-845 (2019). https://doi.org/10.1016/j.ijbiomac.2019.07.176

48. Yu, H.Y., Zhang, D.Z., Lu, F.F., Yao, J.: New approach for singlestep extraction of carboxylated cellulose nanocrystals for their use as adsorbents and flocculants. ACS Sustain. Chem. Eng. 4, 2632-2643 (2016). https://doi.org/10.1021/acssuschemeng.6b001 26

49. El Omari, H., Ablouh, E., Brouillette, F., Taourirte, M., Belfkira, A.: New method for determining paper surface energy per contact angle. Cellulose 26, 9295-9309 (2019). https://doi.org/10.1007/ s10570-019-02695-4

50. Jiang, F., Hsieh, Y.-L.: Cellulose nanocrystal isolation from tomato peels and assembled nanofibers. Carbohydr. Polym. 122, 60-68 (2015). https://doi.org/10.1016/j.carbpol.2014.12.064

51. Kadib, A.E., Finiels, A., Brunel, D.: Sulfonic acid functionalised ordered mesoporous materials as catalysts for fine chemical synthesis. Chem. Commun. 49, 9073-9076 (2013). https://doi.org/ 10.1039/C3CC45160G

52. Chen, S.S., Yu, I.K.M., Tsang, D.C.W., Yip, A.C.K., Khan, E., Wang, L., Ok, Y.S., Poon, C.S.: Valorization of cellulosic food waste into levulinic acid catalyzed by heterogeneous Brønsted acids: Temperature and solvent effects. Chem. Eng. J. 327, 328335 (2017). https://doi.org/10.1016/J.CEJ.2017.06.108

53. George, J., Ramana, K.V., Bawa, A.S.: Bacterial cellulose nanocrystals exhibiting high thermal stability and their polymer nanocomposites. Int. J. Biol. Macromol. 48, 50-57 (2011). https:// doi.org/10.1016/j.ijbiomac.2010.09.013

54. Espino, E., Cakir, M., Domenek, S., Román-Gutiérrez, A.D., Belgacem, N., Bras, J.: Isolation and characterization of cellulose nanocrystals from industrial by-products of Agave tequilana and barley. Ind. Crops Prod. 62, 552-559 (2014). https://doi.org/10. 1016/j.indcrop.2014.09.017

55. Jiang, J., Li, J., Hu, J., Fan, D.: Effect of nitrogen phosphorus flame retardants on thermal degradation of wood. Constr. Build. Mater. 24, 2633-2637 (2010). https://doi.org/10.1016/j.conbu ildmat.2010.04.064

56. Gebke, S., Thümmler, K., Sonnier, R., Tech, S., Wagenführ, A., Fischer, S.: Flame retardancy of wood fiber materials using phosphorus-modified wheat starch. Molecules 25, 335 (2020). https:// doi.org/10.3390/molecules25020335

57. Liu, C., Wang, H., Karim, A.M., Sun, J., Wang, Y.: Catalytic fast pyrolysis of lignocellulosic biomass. Chem. Soc. Rev. 43, 7594-7623 (2014). https://doi.org/10.1039/C3CS60414D

58. Liao, J.J., Latif, N.H.A., Trache, D., Brosse, N., Hussin, M.H.: Current advancement on the isolation, characterization and application of lignin (2020)

59. Antal, M.J., Várhegyi, G., Jakab, E.: Cellulose pyrolysis kinetics: revisited. Ind. Eng. Chem. Res. 37, 1267-1275 (1998). https://doi. org/10.1021/ie970144v

Publisher's Note Springer Nature remains neutral with regard to jurisdictional claims in published maps and institutional affiliations. 